MATEC Web of Conferences 47, 04009 (2016)

DOI: $10.1051 /$ matecconf/20164704009

CC Owned by the authors, published by EDP Sciences, 2016

\title{
Assessing the Use of Failure Case Studies in Civil Engineering Education
}

\author{
Wael Elleithy ${ }^{1}$, Choong Wee Kang ${ }^{1}$ and Lau Teck Leong ${ }^{1, a}$ \\ ${ }^{1}$ Department of Civil Engineering, University of Nottingham Malaysia Campus, Semenyih 43500, Selangor, Malaysia
}

\begin{abstract}
Civil engineering failures, unfortunately, occur from time to time leading to serious consequences. It is of importance that civil engineering undergraduate students are made aware of cases of failure in the past, and hence, to enhance their ability of identification of potential deficiencies. Investigating past cases of civil engineering failures has been carried out in UNMC for the last five years. The students are required to research, investigate and write essays reporting on these failures, detailing the causes and lessons learned. This study was conducted in order to assess the effectiveness of such approach. The outcomes of this study indicate that the use of civil engineering failure as case studies enhances the students' educational experiences. In addition to the technical learning benefits from past civil engineering failure case studies, there are also impacts on students' attitudes which has significant implications in their expected profession.
\end{abstract}

\section{Introduction}

Many civil engineering educators integrate case-based teaching as an inductive method of teaching, see e.g. [1-11] and the references cited therein. As reported in [9], case studies have potential for positive impacts in the affective domain as well as in the cognitive domain. The study of past cases of failure offers the civil engineering students valuable insights into technical, ethical, and professional issues in civil engineering $[1,2,4,6]$. Approaches for accomplishing this, and the benefits of integration of cases of civil engineering failures are subject of professional discussions [1-9]. A first approach for inclusion of cases of failure into a civil engineering curriculum is to introduce a core or an upper-level module in failure analysis and forensic engineering [2]. However, adding a core module to an already existing full curriculum may lack practicality. A second approach is the inclusion of past civil engineering cases of failure into existing modules $[2,5]$.

In order to enhance the undergraduate students' understanding and learning experience at UNMC, an additional module was incorporated for the past five years that is substantially devoted to investigate cases of major constructed civil engineering projects [10], case studies of major civil engineering projects employing sustainable agenda [11], and past cases of civil engineering failures. The students are free to choose case studies and are required to find, sort, synthesize and present information relating to the main issues surrounding cases of construction, sustainability of major civil engineering projects, and cases of civil engineering failure. Finally, the students report/present their findings in the form of several essays. The outcomes of [10] indicate that the use of past civil

\footnotetext{
${ }^{a}$ Corresponding author : teckleong.lau@nottingham.edu.my
} 
engineering projects as case studies enhances the students' educational experiences in higher education in the context of quality cognitive learning. A great majority of the students reported that the case studies are necessary and beneficial to their educational experience, and should be integrated into further civil engineering modules. The outcomes of [11] indicate that the use of major civil engineering projects employing sustainable agenda as case studies develops the students' appreciation of the contemporary engineered environment and sustainability in civil engineering. A common view by the lecturers and students, as indicated in [11], is that the degree course needs to further cover the key issues of sustainable construction.

This paper reports on the results and assesses the use of failure case studies in civil engineering education. The impacts of the use of failure case studies on students' learning and educational experiences were assessed through surveys and focus group discussions. An outline of the paper is as follows. The employed methodology is presented in the succeeding chapter. The students' and lecturers' feedback are presented and analysed in the Survey Questionnaires chapter.

\section{Methodology}

Surveys were conducted on three different groups of Year 2 and Year 3 students in addition to twelve of civil engineering academics with five to twenty years of teaching experience (Table 1). The questionnaire used in this survey was designed to determine how influential is the civil engineering failure case studies on students' aspiration for an ethical career. Furthermore, the lecturers' and students' views on the extent of coverage and the method of inclusion of cases of civil engineering failures as part of the civil engineering curriculum are evaluated.

Fully completed surveys on the use of past civil engineering failures as case studies were analysed. Simple descriptive statistics was mostly used in summarizing students' and lecturers' responses. When appropriate, differences between different groups' responses are highlighted. The results and analysis are presented in the succeeding chapter.

Table 1. Participating groups of students and lecturers.

\begin{tabular}{|c|c|c|c|c|}
\hline Group & Description & Year of study & Year of survey & Size \\
\hline S1 & Students & $2011-12($ Yr 2) & $2012-13($ Yr 3) & 43 \\
\hline S2 & Students & $2012-13($ Yr 2) & $2012-13($ Yr 2) & 61 \\
\hline S3 & Students & $2013-14($ Yr 2) & $2013-14($ Yr 2) & 43 \\
\hline L & Lecturers & & $2013-14$ & 12 \\
\hline
\end{tabular}

\section{Survey Questionnaires}

\subsection{Students' feedback}

The survey instrument is shown in Table 2(a) and (b). In what follows, the analysis of the students' responses is presented.

Table 2(a). Use of failure case studies in civil engineering - students' survey instrument.

\begin{tabular}{|c|l|}
\hline Q1.a & "Have the investigated cases of failure led to major research studies?" \\
\hline Q1.b & $\begin{array}{l}\text { "Have the civil engineering cases of failure contributed to change in/improvement of the engineering } \\
\text { practice?" }\end{array}$ \\
\hline Q2.a & $\begin{array}{l}\text { "Have the civil engineers who were involved in the design/construction faced any legal/ professional } \\
\text { consequences?" }\end{array}$ \\
\hline Q2.b & $\begin{array}{l}\text { "How do the consequences/liabilities that civil engineers face affect your motivations in becoming a } \\
\text { practicing civil engineer?" }\end{array}$ \\
\hline Q3 & $\begin{array}{l}\text { "Has your study/investigation of past civil engineering failure cases motivated you for a better quality } \\
\text { self-learning?" }\end{array}$ \\
\hline
\end{tabular}


Table 2(b). Use of failure case studies in civil engineering - students' survey instrument.

\begin{tabular}{|c|l|}
\hline Q4 & $\begin{array}{l}\text { "Has your study/investigation of past civil engineering failure cases motivated you to practice } \\
\text { ethically in your future career?" }\end{array}$ \\
\hline Q5 & "In which way should the case studies be included in civil engineering modules?" \\
\hline Q6 & "Should the civil engineering failure cases be included in further civil engineering modules?" \\
\hline
\end{tabular}

Q1.a: 78\% of the students indicated that the investigated cases of failure have led to major research in civil engineering (Figure 1). 59\%, 85\%, and 78\% were S1, S2 and S3 students, respectively. The response of group S1 students' with regards to project led research was expected as the survey was conducted while this group of students is in their third year.

Q1.b: The results (Figure 2) indicate that the students have developed an increased awareness of lessons learned from failure cases and the consequent improvement of the engineering practice.

Q2.a: $77 \%$ of the students indicated that the engineers involved in the investigated civil engineering cases of failure faced legal/professional consequences (Figure 3). 78\%, 77\%, and 76\% were S1, S2 and S3 students, respectively. Among the three different groups, the reported levels of awareness of consequences faced by engineers were nearly identical.

Q2.b: $63 \%$ of the students were affected positively (Figure 4). 70\%, 54\%, and 68\% were S1, S2 and S3 students, respectively. An increase in taking the challenges positively was observed was observed for S1 students.

Q3: Among the three different groups of students, a nearly identical level of motivation for better self-learning was reported (Figure 5).

Q4: 92\% of the students have been motivated for ethical practice (Figure 6). 98\%, 90\%, and 92\% were S1, S2 and S3 students, respectively. An increased motivation was observed for S1 students.

Q5: Analysis of results (Figure 7) indicates an increased preference of group/discussion based inclusion for $\mathrm{S} 1$ students.

Q6: 85\% of the students prefer inclusion of case studies in further modules (Figure 8). A slight decrease in desire for inclusion in further modules was noted for S1 students.

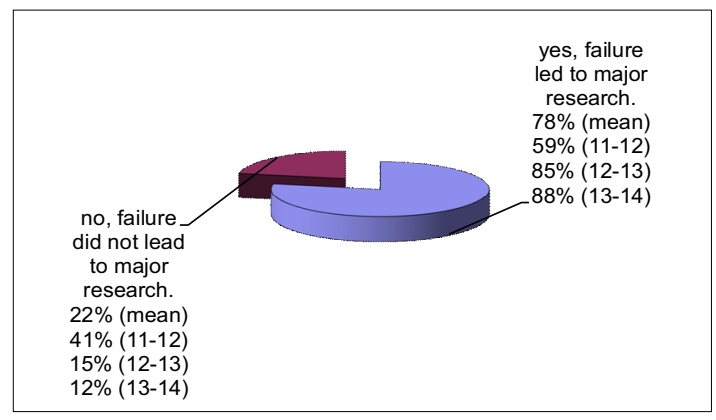

Figure 1. Leading to major research.

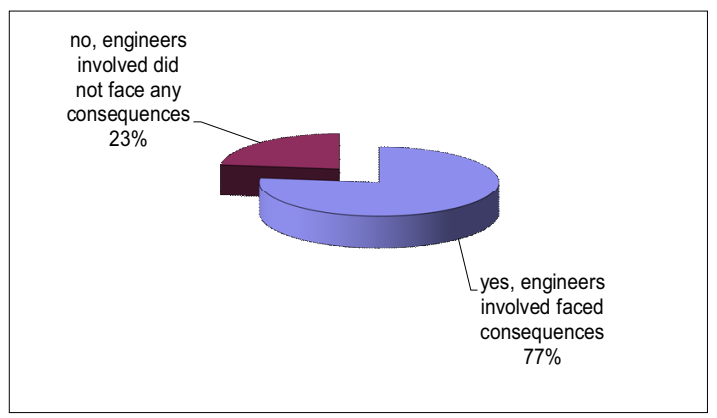

Figure 3. Consequences faced.

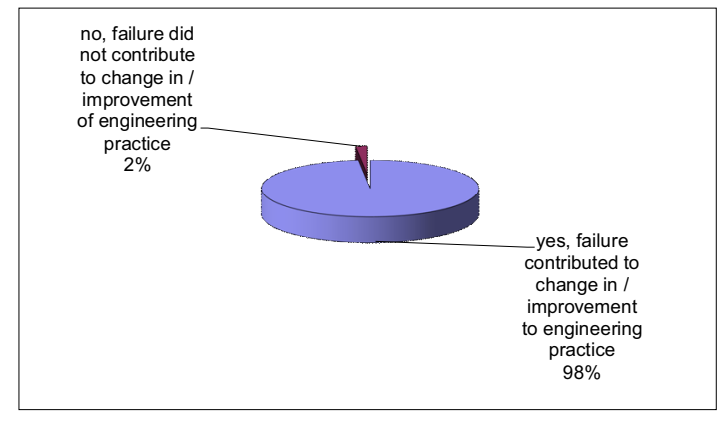

Figure 2. Contribution to changes in practice.

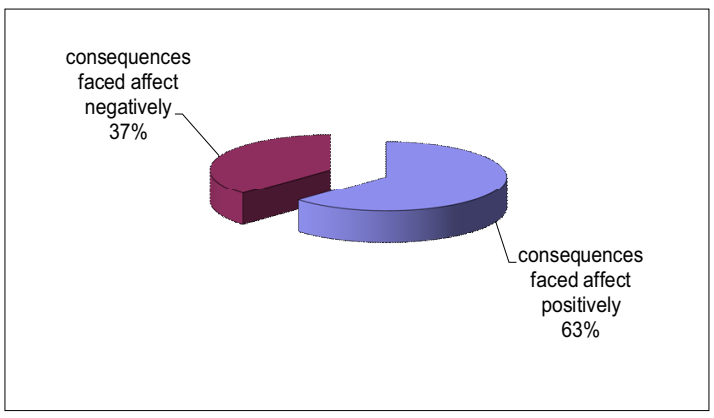

Figure 4. Motivation - practicing civil engineers. 


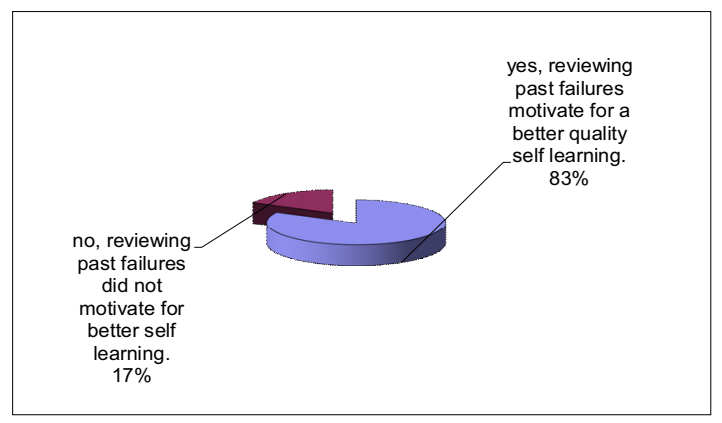

Figure 5. Motivation for self-learning.

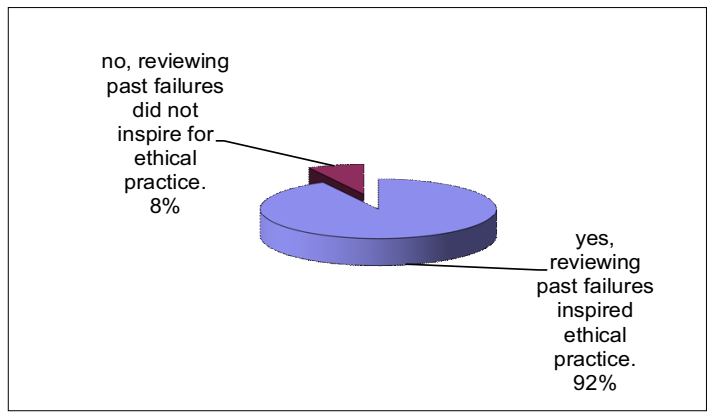

Figure 6. Motivation for ethical practice.

It is noted that the trend of the students' responses in this section is comparable to those reported in [10] and [11], on the use of case studies in construction of major civil engineering projects and sustainability of major civil engineering projects, respectively.

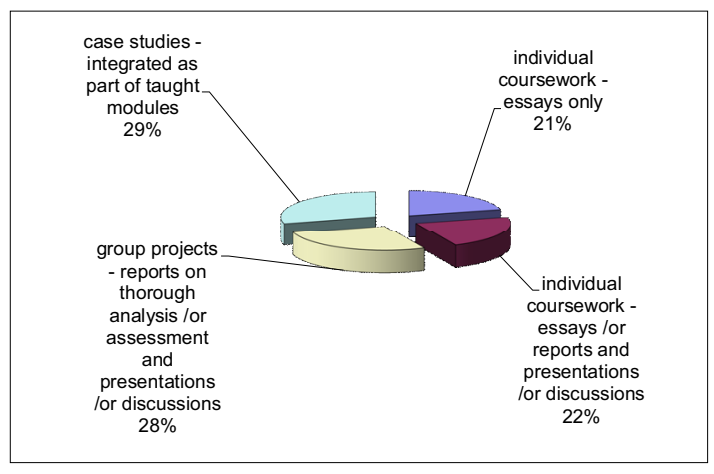

Figure 7. Preferred method of inclusion.

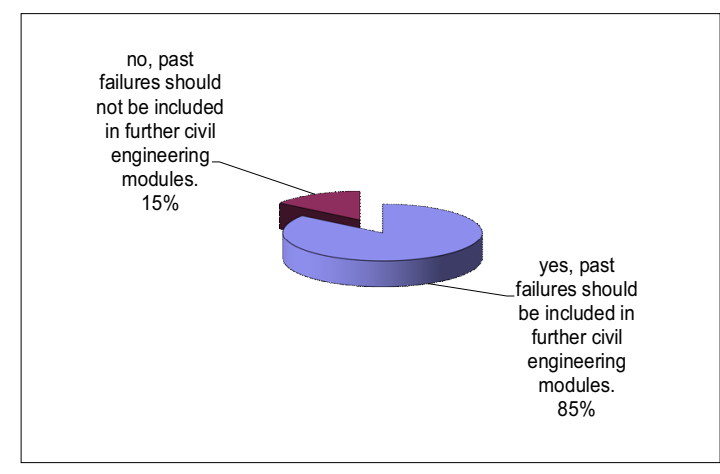

Figure 8. Inclusion in further modules.

\subsection{Lecturers' feedback}

A questionnaire comprising 5 questions was designed to investigate the lecturers' views on use of past civil engineering failures as case studies (Table 3).

Table 3. Use of failure case studies in civil engineering - lecturers' survey instrument.

\begin{tabular}{|c|c|}
\hline Q1 & $\begin{array}{l}\text { "How would the consequences/liabilities that are faced by civil engineers involved in the } \\
\text { design/construction of the studied/investigated past civil engineering failure cases affect the students' } \\
\text { motivation in becoming civil engineers?" }\end{array}$ \\
\hline Q2 & $\begin{array}{l}\text { "Would the study/investigation of past civil engineering failure cases motivate the students for a } \\
\text { better quality self-learning?" }\end{array}$ \\
\hline Q3 & $\begin{array}{l}\text { "Would the study/investigation of past civil engineering failure cases motivate students to practice } \\
\text { ethically in their future career?" }\end{array}$ \\
\hline Q4 & $\begin{array}{l}\text { "Would the study/investigation into critical information, such as: whether there were public enquiries } \\
\text { held and the causes of failure of the studied/investigated cases lead to a better students' } \\
\text { understanding in Civil Engineering?" }\end{array}$ \\
\hline Q5.a & "Should past civil engineering failure cases be included in further civil engineering modules?" \\
\hline Q5.b & $\begin{array}{l}\text { "Indicate how would be the most appropriate methods to be included in the civil engineering } \\
\text { modules." }\end{array}$ \\
\hline
\end{tabular}


In what follows, the analysis of the lecturers' responses is presented:

Q1: The lecturers' expectations (Figure 9) exceeded those of S1, S2 and S3 students by 13\%, 29\% and $15 \%$, respectively.

Q2: The students' expectations (Figure 5) exceeded the reported lecturers' ones (Figure 10).

Q3: As in Q2, the students' expectations (Figure 6) exceeded those of the surveyed lecturers (Figure 11). The reported results of Q2 and Q3 may be attributed to students' enthusiasm.

Q4: The results (Figure 12) indicate that $75 \%$ of the lecturers believe that investigation into critical information leads to a better students' understanding in civil engineering.

Q5.a: $83 \%$ of the lecturers suggested that civil engineering failure cases should be included in further civil engineering modules (Figure 13).

Q5.b: The results (Figure 14) indicate that 39\% and 28\% of the lecturers recommend having the case studies as group and individual projects coupled with presentations/discussions, respectively. $28 \%$ of lecturers recommend having the case studies as parts of the taught modules. $5 \%$ of the lecturers recommend maintaining the case studies in essays form.

It is noted that the trend of the lecturers' responses in this section is comparable to those reported on the use of case studies in sustainability of major civil engineering projects [11].

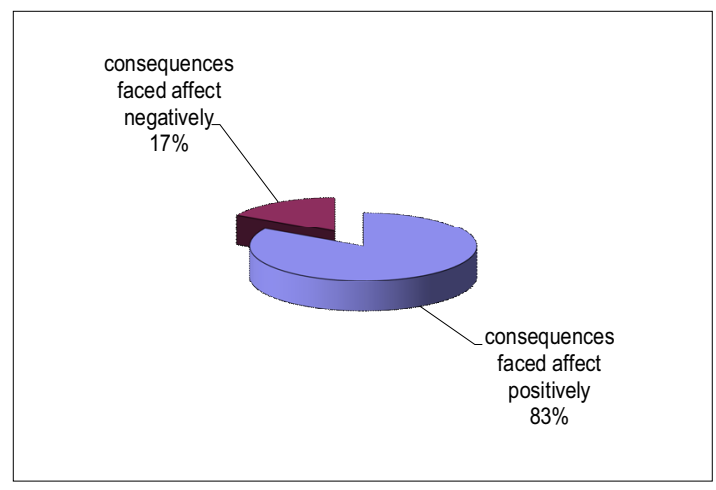

Figure 9. Motivation - practicing civil engineers.

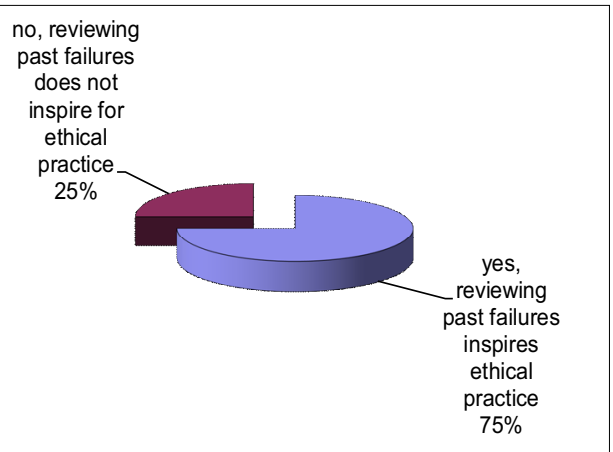

Figure 11. Motivation - ethical practice.

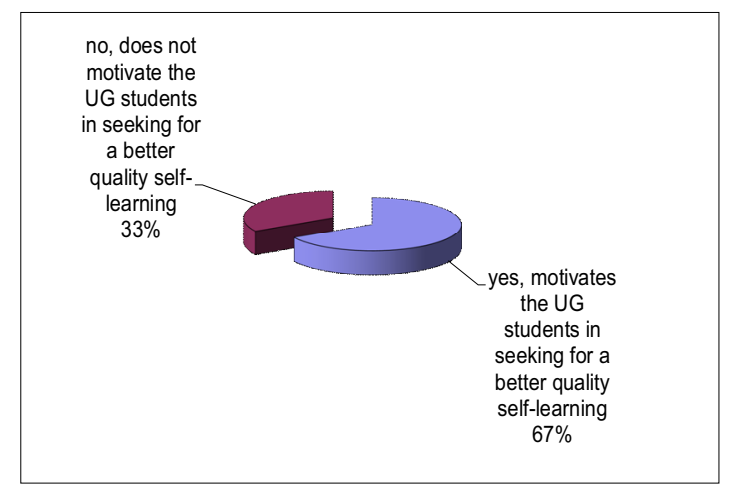

Figure 10. Motivation - self-learning.

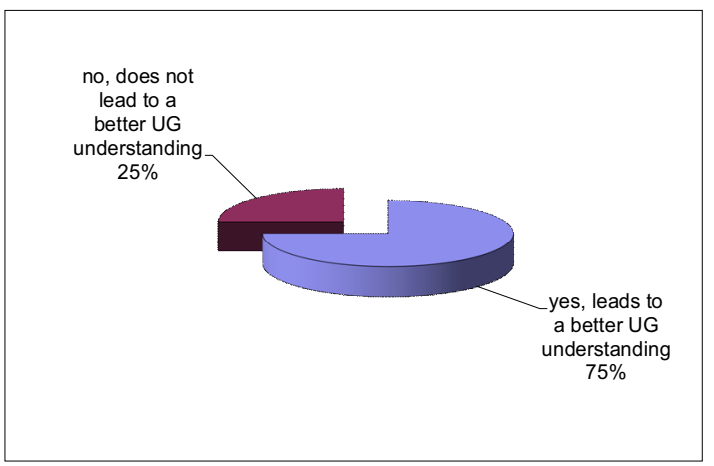

Figure 12. Investigation - critical information. 


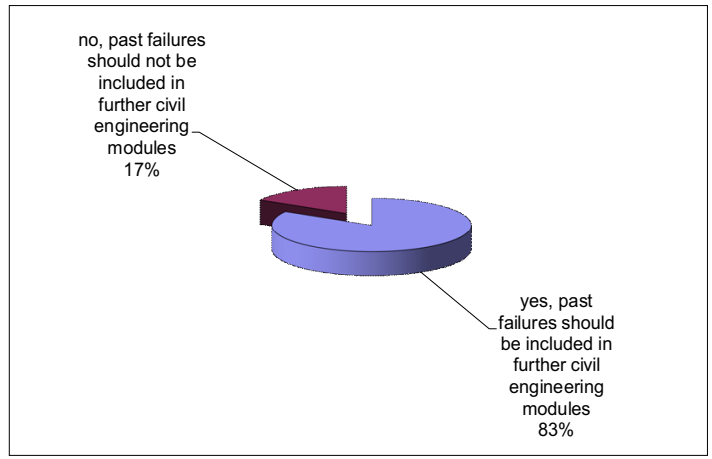

Figure 13. Inclusion of cases of failure.

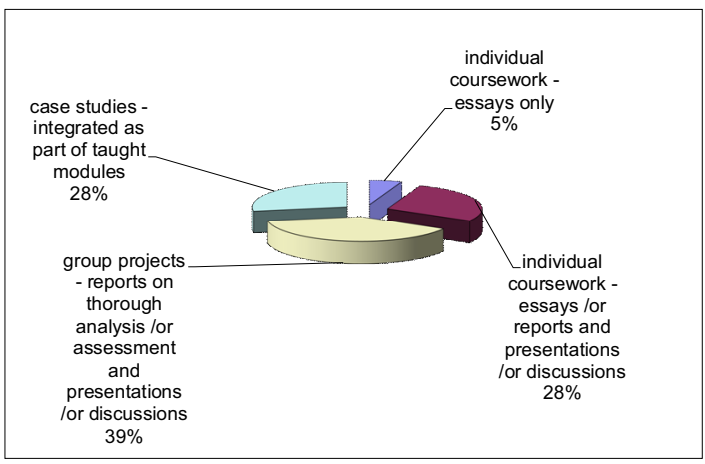

Figure 14. Integration of cases of failure.

\section{Summary}

Lessons learned from case studies have substantially affected the practice of civil engineering. According to Delatte et al. [9] "the history of the development of practice in many engineering disciplines is, in large part, the story of failures, both imminent and actual, and of the changes to designs, standards and procedures made as the result of timely interventions or forensic analyses".

It is of importance that civil engineering undergraduate students are made aware of cases of failure in the past. In this study, data was collected from academics involved in supervising students carrying out case studies of civil engineering failures and different groups of civil engineering students about their perceptions of this approach in improving student technical abilities and professional and ethical responsibilities. The study provided some insights into the value that civil engineering academics and students place on the use of failure cases in civil engineering.

The authors believe that civil engineering failure cases should be spread through the course modules, rather than developing and delivering specific modules focusing in failure analysis and forensic engineering. The authors, furthermore, believe that civil engineering failure cases make students aware of their professional/ethical responsibilities, and increase students' ability to apply knowledge of civil engineering to real life problems. This confirms with the surveyed students' and lecturers' responses, and the results presented in [9].

The presented results and analysis give only a brief of the lecturers' and different groups of civil engineering students' views at UNMC. A comparative investigation is underway of the appreciation, attitudes and perceptions regarding civil engineering failure cases in civil engineering involving civil engineering academics and students at three different campuses of the University of Nottingham. Comparison between students in successive years of the program and in different campuses would be strengthened by calculation of statistical significance for the given populations, and sample sizes needed to obtain sufficient statistical power.

\section{Acknowledgement}

The support of the University of Nottingham Malaysia Campus is acknowledged.

\section{References}

[1] N.J. Delatte, Using failure case studies in civil engineering education, Forensic Engineering, K.L. Rens, O. Rendon-Herrero, P.A. Bosela, eds., ASCE, 430-440, (2000).

[2] N.J. Delatte, K.L. Rens, Forensics and case studies in civil engineering education: State of the art, Journal of Performance of Constructed Facilities, 16, 98-109, (2002).

[3] N.J. Delatte, Using failure case studies in civil engineering courses, Proc. of the 2003 American Society for Engineering Education Annual Conference and Exposition, Nashville, (2003). 


\section{IConCEES2015}

[4] N.J. Delatte, Case studies for civil engineering educators, Proc. of the 2005 Forensic Engineering Symposium/Structures Congress, New York, 1539-1555, (2005).

[5] A. Adekoya and J. Patel, The use of failure case studies to enhance students' understanding of structural behavior and ethics, International Conference on Engineering Education,15-20, (2006).

[6] N. Delatte, Beyond Failure: Forensic Case Studies for Civil Engineers, ASCE Publications, (2009).

[7] N. Delatte, Failure literacy in structural engineering, Engineering Structures, 32, 1952-1954, (2010).

[8] T.A. Newson and N.J. Delatte, Case methods in civil engineering teaching, Canadian Journal of Civil Engineering, 38, 1016-1030, (2011).

[9] N. Delatte, P. Bosela J. Bagakas, Implementation and assessment of failure case studies in the engineering curriculum, Forensic Engineering, 458-466, (2012).

[10]T.L. Lau and W. Elleithy, The use of past projects as means to enhance the education experience of civil engineering students, Applied Mechanics and Materials, 357-360, 2634-2639, (2013).

[11]W. Elleithy and T.L. Lau, Sustainable construction - the use of case studies in civil engineering education, International Conference on Learning and Teaching in Computing and Engineering, Kuching, 151-157, (2014). 